University of Rhode Island

DigitalCommons@URI

\title{
Location and Mechanism of the Little Skull Mountain Earthquake as Constrained by Satellite Radar Interferometry and Seismic Waveform Modeling
}

\author{
Brian K. Savage \\ University of Rhode Island, savage@uri.edu \\ Rowena B. Lohman \\ Mark Simons
}

Follow this and additional works at: https://digitalcommons.uri.edu/geo_facpubs

Terms of Use

All rights reserved under copyright.

\section{Citation/Publisher Attribution}

Lohman, R. B., M. Simons, and B. Savage, Location and mechanism of the Little Skull Mountain earthquake as constrained by satellite radar interferometry and seismic waveform modeling, J. Geophys. Res., 107(B6), doi: 10.1029/2001JB000627, 2002.

Available at: http://dx.doi.org/10.1029/2001JB000627

This Article is brought to you for free and open access by the Geosciences at DigitalCommons@URI. It has been accepted for inclusion in Geosciences Faculty Publications by an authorized administrator of DigitalCommons@URI.For more information, please contact digitalcommons-group@uri.edu. 


\title{
Location and mechanism of the Little Skull Mountain earthquake as constrained by satellite radar interferometry and seismic waveform modeling
}

\author{
Rowena B. Lohman, Mark Simons, and Brian Savage \\ Seismological Laboratory, California Institute of Technology, Pasadena, California, USA \\ Received 23 May 2001; revised 23 October 2001; accepted 28 October 2001; published 19 June 2002.
}

[1] We use interferometric synthetic aperture radar (InSAR) and broadband seismic waveform data to estimate source parameters of the 29 June 1992, $M_{s} 5.4$ Little Skull Mountain (LSM) earthquake. This event occurred within a geodetic network designed to measure the strain rate across the region around Yucca Mountain. The LSM earthquake complicates interpretation of the existing GPS and trilateration data, as the earthquake magnitude is sufficiently small that seismic data do not tightly constrain the epicenter but large enough to potentially affect the geodetic observations. We model the InSAR data using a finite dislocation in a layered elastic space. We also invert regional seismic waveforms both alone and jointly with the InSAR data. Because of limitations in the existing data set, InSAR data alone cannot determine the area of the fault plane independent of magnitude of slip nor the location of the fault plane independent of the earthquake mechanism. Our seismic waveform data tightly constrain the mechanism of the earthquake but not the location. Together, the two complementary data types can be used to determine the mechanism and location but cannot distinguish between the two potential conjugate fault planes. Our preferred model has a moment of $\sim 3.2 \times 10^{17} \mathrm{~N} \mathrm{~m}\left(M_{w} 5.6\right)$ and predicts a line length change between the Wahomie and Mile geodetic benchmarks of $\sim 5 \mathrm{~mm}$. INDEX TERMS: 1208 Geodesy and Gravity: Crustal movements - intraplate (8110); 1242 Geodesy and Gravity: Seismic deformations (7205); 1243 Geodesy and Gravity: Space geodetic surveys; 7230 Seismology: Seismicity and seismotectonics; 8110 Tectonophysics: Continental tectonics - general (0905); 7215 Seismology: Earthquake parameters; 7260 Seismology: Theory and modeling; KEYWORDS: InSAR, joint inversion, seismic, Yucca Mountain

\section{Introduction}

[2] Yucca Mountain, a proposed long-term $\left(10^{3}-10^{5}\right.$ years) disposal site for high-level radioactive waste, is located within the Nevada Test Site in the southwestern Basin and Range province (Figure 1). The Basin and Range is an extensional province characterized by Cenozoic faulting and volcanism. Estimates of the current earthquake and volcanic hazard of the proposed site are complicated by the very low strain rates and short period of time within which they have been measured geodetically (i.e., $<20$ years). As a result, strain rates derived from the long-term geologic record may not be representative of current conditions since the space-time dependence of strain is not well understood [e.g., Wallace, 1984].

[3] Yucca Mountain lies within the southwestern Nevada volcanic field, a series of middle Miocene (15-7.5 Ma) silicic ash flow tuffs that have been tilted slightly eastward since their formation [Frizzell and Shulters, 1990; Sawyer et al., 1994]. Several small basaltic eruptions occurred during the Quaternary within 10-20 km of Yucca Mountain, with estimates of the most recent age at 81-77 ka [Zreda et al.,

Copyright 2002 by the American Geophysical Union. 0148-0227/02/2001JB000627\$09.00
1993; Heizler et al., 1999]. Crater Flat and Jackass Flat to the west and east of the site (Figure 1) both contain active faults [Ferrill et al., 1996; Fridrich, 1999; Fridrich et al., 1999].

[4] A network of geodetic bench marks was established in 1983 to characterize the deformation across this region [Savage et al., 1994]. This network has been subsequently resurveyed in campaigns using both trilateration and Global Positioning System (GPS) surveys. A trilateration survey using measurements from 1983, 1984, and 1993 [Savage et al., 1994] indicates $8 \pm 20$ nstrain $\mathrm{yr}^{-1}$ of strain accumulation in a $\mathrm{N} 65^{\circ} \mathrm{W}$ direction. A reestimate of the strain rate using campaign GPS observations spanning 1991-1997 suggests strain accumulation of $50 \pm 9$ nstrain $\mathrm{yr}^{-1}$ in the $\mathrm{N} 65^{\circ} \mathrm{W}$ direction [Wernicke et al., 1998].

[5] Differences between these two studies depend, in part, on the treatment of the $M_{s} 5.4$ Little Skull Mountain (LSM) earthquake that occurred on 29 June 1992, 30 km to the southeast of Yucca Mountain (Figure 1). The LSM earthquake was small enough that we expect it to affect only the southeasternmost stations in either network, most notably the horizontal changes in line length, $\Delta L_{w m}$, between the Wahomie and Mile bench marks. While the mechanism of the earthquake is constrained from seismic studies (Table 1), determining the fault area and which nodal plane ruptured is difficult due to the small size of 


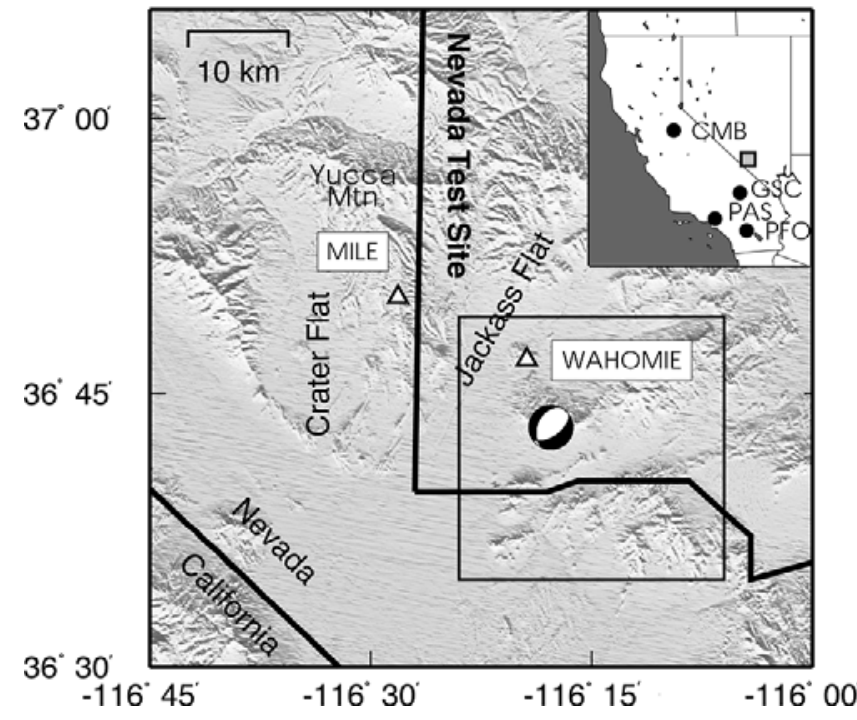

Figure 1. Shaded relief map showing the Mile and Wahomie geodetic bench marks as triangles, the LSM focal mechanism from the Southern Great Basin Seismic Network (SGBSN), and the boundary of the Nevada Test Site. The box shows the location of Figure 2. The inset in the top right indicates the locations of seismic stations (CMB, GSC, PAS, and PFO) used in this study. Mercator projection.

the earthquake. In addition, the seismically located epicenters vary over a spatial range of $\sim 11 \mathrm{~km}$ (Table 1 ). Studies of aftershock hypocenters show that they cluster near the SE dipping plane [Harmsen, 1994; Meremonte et al., 1995; Smith et al., 2000]. On the basis of the orientation of surface faults in the area, Wernicke et al. [1998] prefer the NW dipping plane. A model with a finite dislocation on the SE dipping plane in an elastic half-space $\left[\right.$ Okada, 1985] predicts horizontal elongation of $\Delta L_{w m}$ by $\sim 7 \mathrm{~mm}$, while slip on the NW dipping plane predicts $\Delta L_{w m}$ changes of $<1 \mathrm{~mm}$ [Wernicke et al., 1998].

[6] The interpretations of Savage et al. [1999] and Wernicke et al. [1998] differ in that they use seismic locations for the earthquake that are several kilometers apart (Figure 2). Both studies assume a fault area of $5 \times 5 \mathrm{~km}$, but Wernicke et al. [1998] assume that the two planes that they model share a common base, not their center. This assumption results in the top of the NW dipping plane being around $6 \mathrm{~km}$ to the southeast of their candidate SE dipping plane, such that models using the NW dipping plane affect the geodetic bench mark Wahomie much less than those using the SE dipping plane.

[7] We investigate the mechanism and location of the LSM earthquake using interferometric synthetic aperture radar (InSAR) data from the ERS 1 satellite and regional broadband seismic waveform data. In the process of determining the best fitting earthquake parameters we demonstrate the complementary nature of the InSAR and seismic data for use in studies requiring precise earthquake locations.

\section{InSAR and Seismic Waveform Data}

[8] We use ROI PAC, the California Institute of Technology/Jet Propulsion Laboratory InSAR processing suite,

Table 1. Little Skull Mountain Earthquake Parameter Estimates ${ }^{\mathrm{a}}$

\begin{tabular}{|c|c|c|c|c|c|c|c|}
\hline Reference/Model & Lat, deg & Long, deg & Depth, km & Strike, deg & Dip, deg & Rake, deg & Moment, $\mathrm{N} \mathrm{m}$ \\
\hline Romanowicz et al. [1993] ${ }^{\mathrm{b}}$ & 36.66 & 116.23 & 8 & 43 & 66 & -73 & $3.5 \times 10^{17}$ \\
\hline Romanowicz et al. $[1993]^{\mathrm{c}}$ & 36.66 & 116.23 & 8 & 34 & 44 & -70 & $2.6 \times 10^{17}$ \\
\hline Walter $[1993]^{\mathrm{d}}$ & 36.718 & 116.289 & 10 & 35 & 54 & -87 & $4.1 \times 10^{17}$ \\
\hline Harmsen $[1994]^{\mathrm{e}}$ & 36.72 & 116.295 & 10 & 55 & 56 & -72 & - \\
\hline Zhao and Helmberger [1994] $]^{\mathrm{f}}$ & 36.7 & 116.25 & 11 & 45 & 55 & -60 & $3.0 \times 10^{17}$ \\
\hline Meremonte et al. [1995] & 36.72 & 116.295 & $10-11$ & 55 & 56 & -72 & - \\
\hline Wernicke et al. [1998], SE & 36.707 & 116.263 & 8.0 & 35 & 54 & -90 & $4.5 \times 10^{17}$ \\
\hline Wernicke et al. [1998], NW & 36.726 & 116.299 & 7.5 & 215 & 36 & -90 & $4.5 \times 10^{17}$ \\
\hline Savage et al. [1999] & 36.741 & 116.312 & 8.3 & 55 & 56 & -90 & $4.0 \times 10^{17}$ \\
\hline Smith et al. [2000] & 36.719 & 116.296 & 9.0 & 60 & 70 & -70 & $4.5 \times 10^{17}$ \\
\hline \multicolumn{8}{|c|}{ This Study InSAR- Only } \\
\hline Half-space & 36.743 & 116.242 & 10.6 & 47 & 38 & -55 & $4.4 \times 10^{17}$ \\
\hline Standard Southern California ${ }^{g}$ & 36.742 & 116.247 & 11.1 & 39 & 37 & -61 & $5.8 \times 10^{17}$ \\
\hline Mojave $^{\text {h }}$ & 36.745 & 116.243 & 11.2 & 52 & 40 & -51 & $5.0 \times 10^{17}$ \\
\hline \multicolumn{8}{|c|}{ This Study Seismic-Only } \\
\hline Standard Southern California ${ }^{\mathrm{g}}$ & 36.613 & 116.441 & 10.9 & 35 & 48 & -80 & $3.32 \times 10^{17}$ \\
\hline Mojave $^{\mathrm{h}}$ & 36.597 & 116.439 & 11.8 & 35 & 43 & -81 & $2.47 \times 10^{17}$ \\
\hline \multicolumn{8}{|c|}{ This Study Joint Seismic and InSAR } \\
\hline Standard Southern California ${ }^{g}$ & 36.747 & 116.283 & 9.5 & 38 & 58 & -76 & $4.1 \times 10^{17}$ \\
\hline Mojave $^{\text {h }}$ & 36.745 & 116.285 & 9.4 & 36 & 58 & -78 & $3.2 \times 10^{17}$ \\
\hline
\end{tabular}

${ }^{a}$ Latitude, longitude, and depth for finite fault planes refer to the center of the fault plane. Moment is calculated using $\mu=35$ GPa for the Mojave model, $42 \mathrm{GPa}$ for the Standard Southern California model, and $33 \mathrm{GPa}$ for all others.

${ }^{\mathrm{b}}$ Regional surface wave.

${ }^{\mathrm{c}}$ Regional body wave.

${ }^{\mathrm{d}}$ Single very broadband station.

e Aftershock hypocenter.

${ }^{\mathrm{f}}$ Broadband waveform.

${ }^{g}$ Hadley and Kanamori [1977].

h Jones and Helmberger [1998]. 


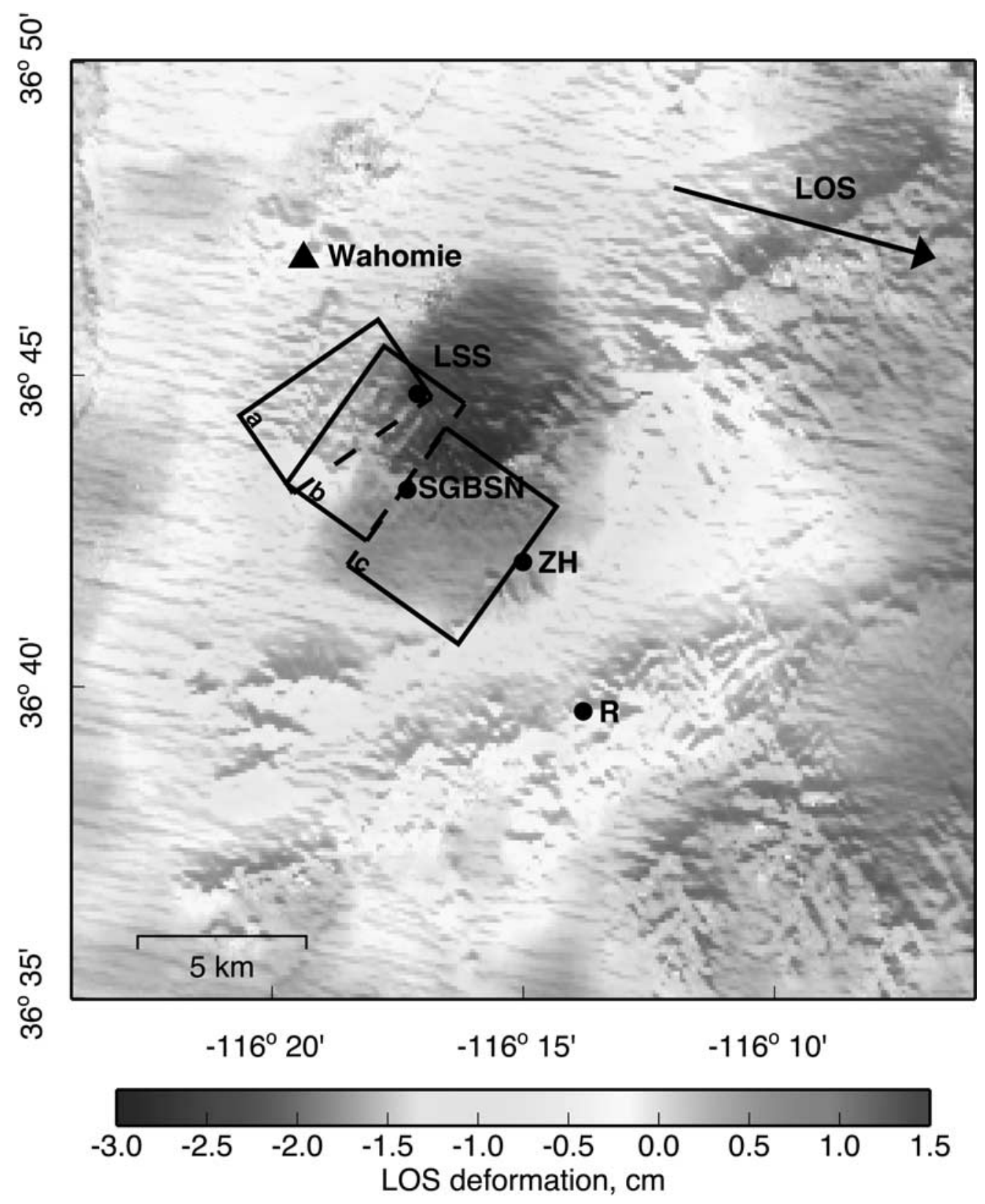

Figure 2. Averaged interferometric LOS displacement field used in the inversions. The arrow indicates the surface projection of the LOS vector from the ground to the satellite. Small-scale fluctuations in the displacement field are due to tropospheric and ionospheric variations between scene acquisition dates. Geodetic bench mark Wahomie is shown as a solid triangle. Solid circles indicate the LSM epicenter locations from the Southern Great Basin Seismic Network (SGBSN), Zhao and Helmberger [1994] (ZG), Romanowicz et al. [1993] (R) and from our joint inversion using the Mojave layered model (LSS). Rectangles show the map view projections of the fault planes used by Savage et al. [1999] (box a) and the SE dipping (box b) and NW dipping (box c) planes of Wernicke et al. [1998]. The dashed line indicates the bottom of the plane in all cases. Mercator projection. See color version of this figure at back of this issue.

to produce unwrapped geocoded interferograms. We combine the one existing SAR image acquired before the earthquake with three postearthquake images to create three interferograms spanning different time periods (Table 2). We neglect any potential time-dependent postseismic deformation and average the three interferograms to reduce ionospheric and tropospheric noise. As there is only one preseismic scene, any noise within it is carried through to our final averaged interferogram. We remove the effects of topography in the interferograms using a 90-m digital elevation model (http://earthexplorer.usgs.gov), leaving a measurement of surface deformation in the satellite lineof-sight (LOS) direction (Figure 2).

[9] The relative LOS displacement reaches a maximum of $2.4 \mathrm{~cm}$ across an elliptical region in the center of the interferogram (Figure 2). Because the LOS vector is $\sim 23^{\circ}$ 
Table 2. ERS 1 Data Used in This Study ${ }^{\mathrm{a}}$

\begin{tabular}{|c|c|c|c|c|c|}
\hline Date & Track & Frame & Orbit & $B_{\text {perp }}, \mathrm{m}$ & $H_{a}, \mathrm{~m}$ \\
\hline 24 April 1992 & 399 & 2871 & 4051 & - & - \\
\hline 14 May 1993 & 399 & 2871 & 9562 & 62 & 128 \\
\hline 18 June 1993 & 399 & 2871 & 10063 & 40 & 198 \\
\hline 24 Sept. 1995 & 399 & 2871 & 21930 & 131 & 60 \\
\hline
\end{tabular}

from vertical, we infer that this deformation is mostly due to subsidence. We interpret the smaller amorphous features, with magnitudes of around $1 \mathrm{~cm}$ and dimensions of $1-5 \mathrm{~km}$ that are visible across the image, as radar phase delays introduced by tropospheric and ionospheric perturbations. These delays are $\sim 20 \%$ of the main earthquake signal and therefore introduce a large error term that is difficult to quantify. Only data from descending orbits are available; therefore only one component of the displacement field is observable. Since we can only measure deformation in the LOS direction, we must rely on models of coseismic deformation in order to make predictions of $\Delta L_{w m}$. In addition, the atmospheric errors are large enough that comparisons of individual points of the interferogram are unreliable, such that comparisons of models which fit the entire interferogram are more robust than direct measurements of LOS displacement.

[10] We model the InSAR data for the earthquake using a finite dislocation model. We consider both an elastic half-space [Okada, 1985] and the Standard Southern California [Hadley and Kanamori, 1977] and Mojave [Jones and Helmberger, 1998] layered elastic models (Table 3). We sample the interferogram on a nonuniform grid with a spacing proportional to the curvature of the LOS component of the displacement field (M. Simons et al., manuscript in preparation, 2001). This sampling reduces the number of Green's functions that must be evaluated for each iteration and therefore greatly improves the speed of our inversions.

[11] We use regional seismic waveform data for the LSM earthquake recorded at distances of 150 to over $1000 \mathrm{~km}$, at four stations (CMB, GSC, PAS, and PFO) in the TERRAscope and Berkeley Digital Seismic Networks (Figure 1). Seismic data at these ranges are dominated by refracted compressional energy $(P n l)$, reflected shear waves, and large-amplitude surface waves. Refracted energy arrives

Table 3. Layered Elastic Models ${ }^{\mathrm{a}}$

\begin{tabular}{|c|c|c|}
\hline Depth, km & Density, $\mathrm{g} \mathrm{cm}^{-3}$ & $V_{p}, \mathrm{~km} \mathrm{~s}^{-1}$ \\
\hline \multicolumn{3}{|c|}{ Mojave $^{\mathrm{b}}$} \\
\hline 2.5 & 2.40 & 5.00 \\
\hline 5.5 & 2.40 & 5.50 \\
\hline 28.0 & 2.67 & 6.30 \\
\hline Half-space & 3.42 & 7.85 \\
\hline \multicolumn{3}{|c|}{ Standard SoCal } \\
\hline 5.5 & 2.40 & 5.50 \\
\hline 16.0 & 2.67 & 6.30 \\
\hline 35.0 & 2.80 & 6.70 \\
\hline Half-space & 3.00 & 7.80 \\
\hline
\end{tabular}

much earlier than the shear and surface waves, but the waveforms are dominated in amplitude and duration by the later arriving surface waves. Since $P n l$ arrivals are sensitive to the depth of the earthquake and fault plane orientation, we enhance the $P n l$ section of the seismic signal relative to the surface waves using the method of Zhao and Helmberger [1994].

[12] Attempts to fit $P n l$ and surface waves are difficult in absolute time since approximations of the elastic structure of the lithosphere introduce errors into the synthetics. Therefore we shift and filter the data and synthetics so that they only reflect the general properties
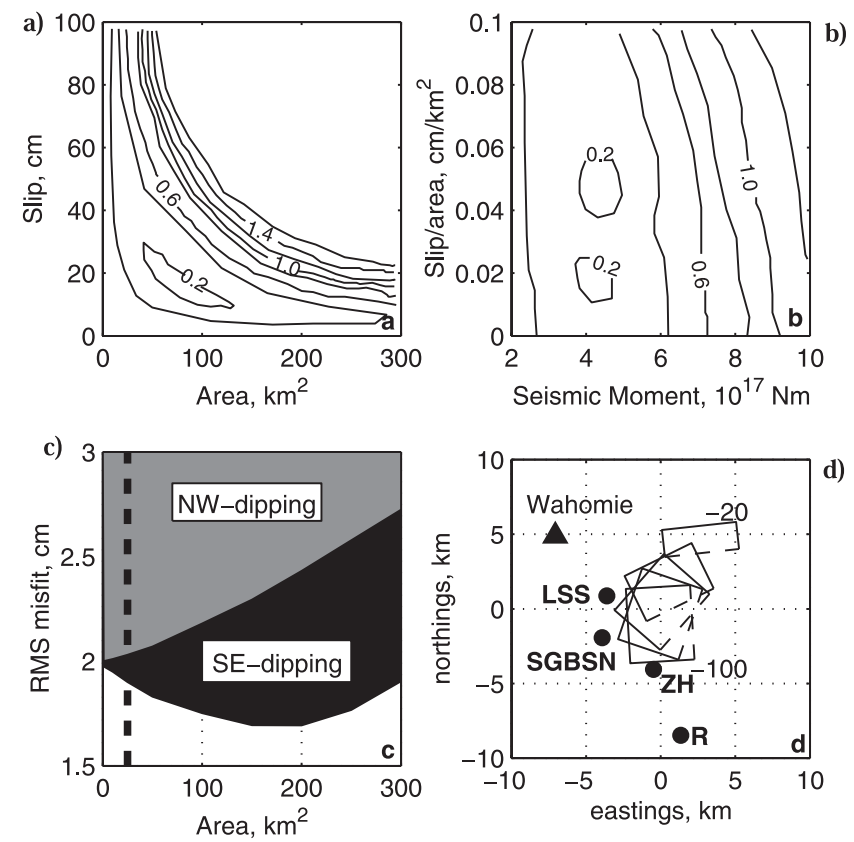

Figure 3. (a) Contours of RMS model misfit versus fault plane area and amount of slip. Misfit continues to increase to the upper right of the panel. (b) Contours of RMS model misfit versus moment and slip/area. Moment is calculated using $\mu=33 \mathrm{GPa}$. (c) Area versus RMS model misfit for SE dipping fault planes (solid) and NW dipping fault planes (shaded). The $25 \mathrm{~km}^{2}$ area used by previous workers is indicated by a heavy dashed line. (d) Map view location of best fitting planes with area $25 \mathrm{~km}^{2}$ and rake fixed at values between $-20^{\circ}$ and $-100^{\circ}$. Solid circles indicate LSM epicenter locations as in Figure 2. All panels show results from inversions using only InSAR data and assuming an elastic half-space. The inversion behavior is similar for the layered spaces and our joint inversions. This and all subsequent maps use a UTM (zone 11) projection. 

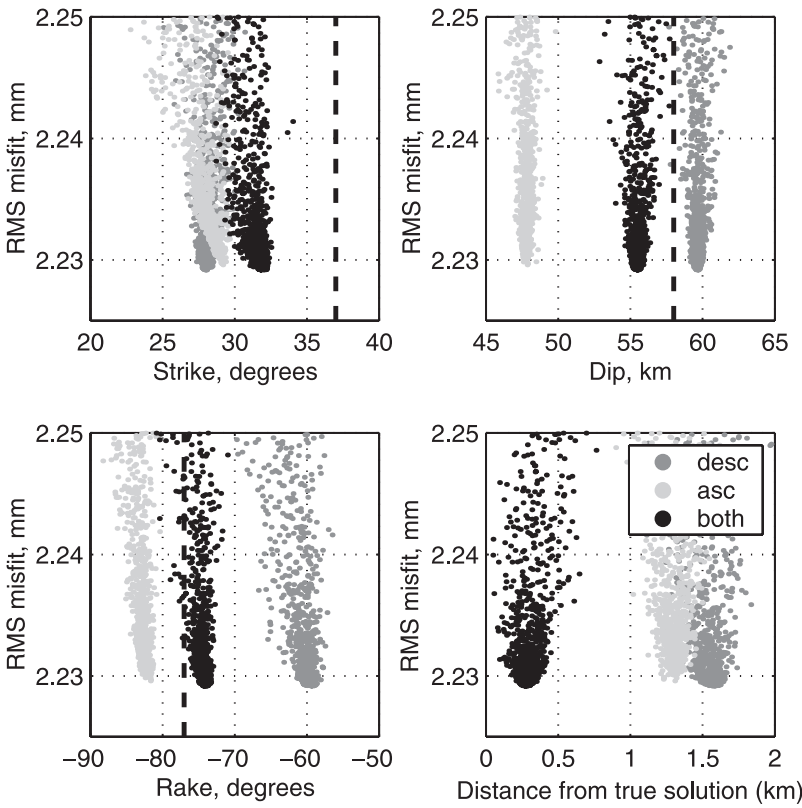

Figure 4. RMS model misfit versus strike, dip, rake, and the absolute distance from the true solution, indicated by the solid dashed line. These inversions use synthetic data with noise taken from the real, observed interferogram. The light and dark shaded dots correspond to models from inversions using just data from ascending or descending satellite tracks. The solid dots are models that use both sets of synthetic data.

of the crust and lithosphere. Aligning the synthetics with the data in time acknowledges that our seismic data lack the power to well resolve the epicenter location. Pnl waveforms are filtered to include higher frequencies $(0.01-0.2 \mathrm{~Hz})$ than the full waveforms $(0.01-0.05 \mathrm{~Hz})$ to better identify the depth phases that constitute Pnl. We compute synthetics using an F-K double integration [Wang and Herrmann, 1980] in both the Standard Southern California and Mojave layered elastic models (Table 3) and compare these synthetics to the data on a point by point basis in a least squares sense.

\section{Source Parameter Inversions}

[13] The root-mean-square (RMS) misfit between the data and our model depends on the value of nine parameters defining the location and orientation of the fault plane and the amount and direction of slip that occurred during the earthquake. Traditional gradient searches may fail to find the true minimum in such a nonlinear problem. Rather than using a grid search to explore the parameter space associated with this event, which involves evaluating the forward model many times in regions with potentially high misfit, we use the Neighborhood Algorithm (NA) developed by Sambridge [1998a, 1998b].

[14] The NA method has advantages over techniques such as genetic algorithms and simulated annealing in that it produces a more complete image of the misfit function over the entire parameter space, while concentrating sampling in the regions with lowest misfit. This approach is important for studies such as ours with multidimensional, nonlinear parameter spaces, where inferring the global minimum is only part of the full characterization of the misfit behavior. The ensemble of models and misfits produced by the NA algorithm illustrates the broadness and uniqueness of the minima and shows the trade-offs that may exist between sets of parameters.

\section{Results and Implications}

[15] For the InSAR-only inversion we allow the inversion to search through the entire possible range for each parameter, letting strike, dip, and rake vary as well as area, location, and amount of slip, all assuming a square fault plane. We find a large trade-off between slip and area (Figure 3a), whereas the seismic moment is well-constrained to be $\sim 4.4 \times 10^{17} \mathrm{~N} \mathrm{~m}\left(M_{w} 5.7\right.$, Figure 3b). Since the area is not well constrained by our data, we adopt a value of $25 \mathrm{~km}^{2}$ as estimated from aftershock distributions [Harmsen, 1994; Meremonte et al., 1995; Smith et al., 2000] and that is used in previous studies [Wernicke et al., 1998; Savage et al., 1999]. This assumption does not affect our conclusions regarding the line length changes between geodetic bench marks Wahomie and Mile. The inversion slightly prefers models with SE dipping planes, but this is only for planes that are larger than $\sim 100 \mathrm{~km}^{2}$ (Figure $3 \mathrm{c}$ ). As the fault planes get smaller, they approach a point source and are, by definition, indistinguishable from each other. Even for the larger fault planes, the difference in misfit is small and our InSAR data cannot unambiguously distinguish between the two potential rupture planes.

[16] When we invert using only the InSAR data and assume a fixed fault area of $25 \mathrm{~km}^{2}$, a search through the

Table 4. Misfit Values Calculated to Data in This Study

\begin{tabular}{|c|c|c|}
\hline Reference/Model & $\begin{array}{l}\text { RMS Misfit, } \\
\text { mm (InSAR) }\end{array}$ & $\begin{array}{l}\text { RMS Misfit, } \\
\text { mm (Seismic) }\end{array}$ \\
\hline Romanowicz et al. $[1993]^{\mathrm{a}}$ & 7.504 & 1.285 \\
\hline Romanowicz et al. $[1993]^{\mathrm{b}}$ & 5.316 & 1.260 \\
\hline Walter $[1993]^{\mathrm{c}}$ & 3.441 & 1.391 \\
\hline Zhao and Helmberger [1994] & 4.172 & 1.287 \\
\hline Wernicke et al. [1998], SE & 4.710 & 1.593 \\
\hline Wernicke et al. [1998], NW & 5.137 & 1.618 \\
\hline Savage et al. [1999] & 4.607 & 2.254 \\
\hline Smith et al. $[2000]^{\mathrm{d}}$ & 4.726 & 1.287 \\
\hline \multicolumn{3}{|l|}{ This Study InSAR-Only } \\
\hline Half-space & 2.616 & 1.444 \\
\hline Standard Southern California ${ }^{\mathrm{f}}$ & 2.455 & 1.426 \\
\hline Mojave $^{g}$ & 2.557 & 1.436 \\
\hline \multicolumn{3}{|l|}{ This study seismic-only } \\
\hline Standard Southern California ${ }^{f}$ & 5.960 & 1.067 \\
\hline Mojave $^{g}$ & 5.743 & 1.086 \\
\hline \multicolumn{3}{|l|}{ This study joint seismic InSAR } \\
\hline Standard Southern California ${ }^{\mathrm{f}}$ & 2.853 & 1.185 \\
\hline Mojave $^{\mathrm{g}}$ & 2.923 & 1.179 \\
\hline $\begin{array}{l}\text { a Regional surface wave. } \\
{ }^{\mathrm{b}} \text { Regional body wave. } \\
{ }^{\mathrm{c}} \text { Single very broadband station. } \\
{ }^{\mathrm{d}} \text { Aftershock hypocenter. } \\
{ }^{\mathrm{e}} \text { Broadband waveform. } \\
{ }^{\mathrm{f}} \text { Hadley and Kanamori [1977]. } \\
{ }^{\mathrm{g}} \text { Jones and Helmberger [1998]. }\end{array}$ & & \\
\hline
\end{tabular}



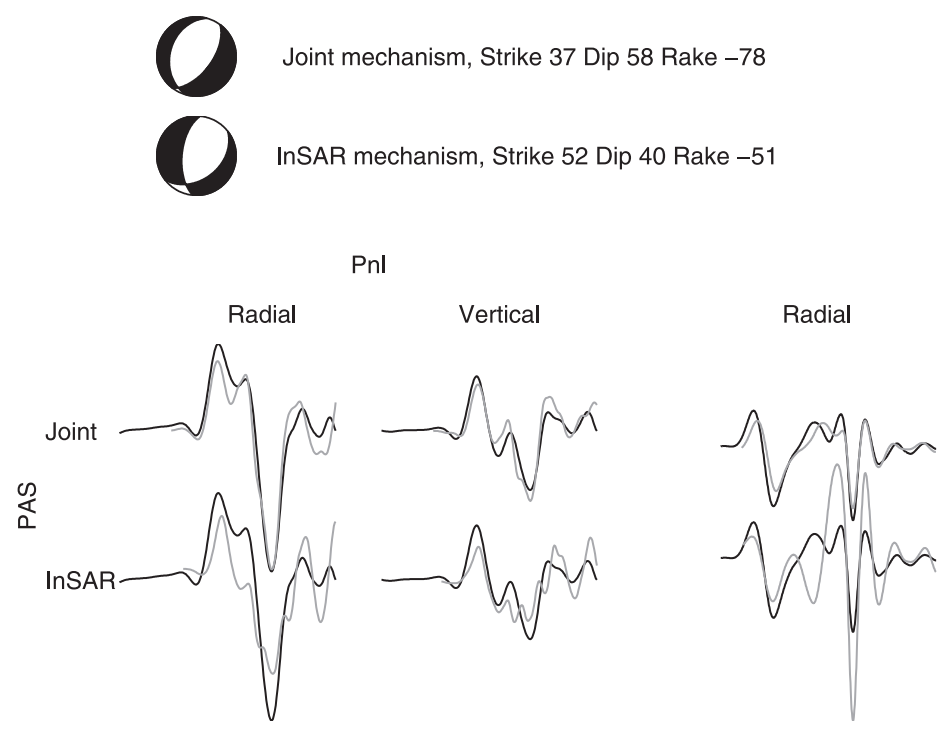

\author{
Full Waveform
}
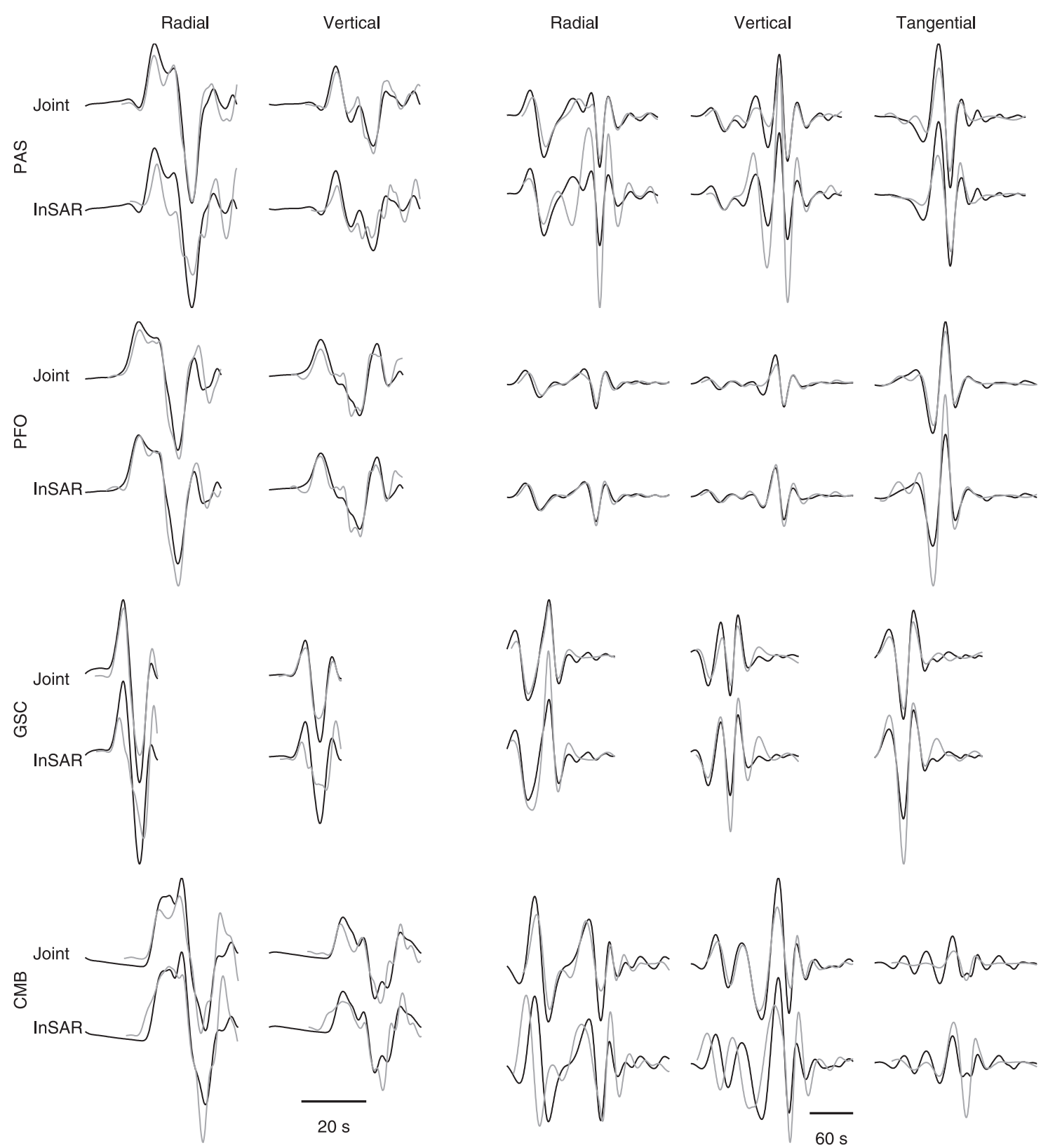

Figure 5. Mechanisms, observed waveforms, and synthetic waveforms from the joint and InSAR-only inversions using the Mojave layered model. Pnl waveforms are filtered from 0.01 to $0.2 \mathrm{~Hz}$, while full waveforms are filtered from 0.01 to $0.05 \mathrm{~Hz}$. Data are shown as solid lines and synthetics as shaded lines. The timescale is shown at the base of each group of plots, with the 20 -s bar referring to the Pnl waveforms and the 60 -s bar referring to the full waveforms.

entire range of potential mechanisms suggests a best fitting mechanism with a rake of $-55^{\circ}$. This estimate of the rake is much shallower (i.e., with a greater component of strikeslip faulting) than predictions from previous seismic studies (Table 1). Figure $3 \mathrm{~d}$ shows the map view locations of best fitting fault planes of area $25 \mathrm{~km}^{2}$ from inversions where we fixed the rake at values between $-20^{\circ}$ and $-100^{\circ}$. All of these models have similar misfits to the InSAR data, illustrating the trade-off between earthquake mechanism and fault plane location inherent with this set 


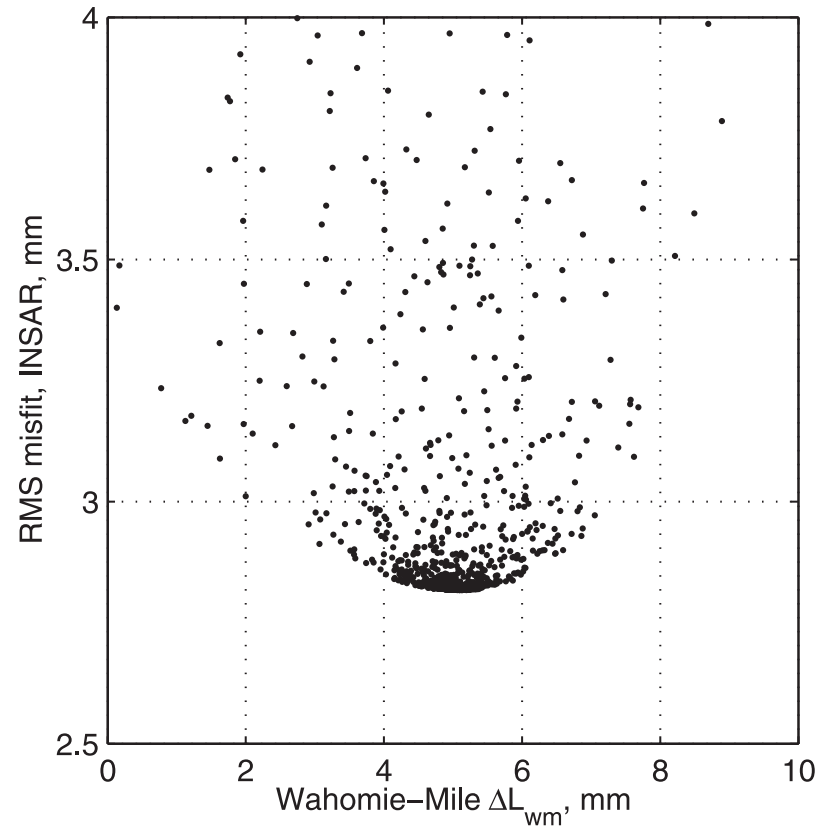

Figure 6. RMS model misfit with the InSAR data versus $\Delta L_{w m}$ for each model tested during our joint inversion using the Mojave layered elastic model.

of InSAR data. If additional InSAR data existed with a different LOS direction, we would be better able to determine the mechanism.

[17] To explore the dependence of these inversions on the availability of different LOS components, we produced synthetic data similar to the LSM earthquake for both ascending and descending tracks. We added several different sets of noise taken from sections of our observed interferogram to this synthetic data. We ran inversions on each data set separately and then compared them to the inversion using both data sets simultaneously. Figure 4 shows the RMS value versus strike, dip, rake, and the absolute distance from the true solution for models produced during these inversions. As expected, for each parameter the inversion using both LOS directions (solid dots) comes closest to the real value used to compute the synthetic data. For this example, we find that we can estimate the hypocenter location to within half a kilometer.

[18] Despite the trade-off between fault area and slip, as well as between location and mechanism, some earthquake parameters are well determined by the InSAR data. The InSAR-only inversion using an elastic half-space model tightly constrains $\Delta L_{w m}$ to be around $6 \mathrm{~mm}$. InSAR-only inversions using both the Standard Southern California and Mojave layered elastic models predict results similar to that of the half-space inversion, except that the inferred hypocenter depths are around 400-500 $\mathrm{m}$ deeper and the moment is slightly larger for the layered models (Table 1). Inversions in layered elastic models involve a trade-off between the layered structure and the distribution of slip. Both of the layered models that we use have less rigid layers above the earthquake than below, which results in a greater predicted depth than from inversions in a halfspace. In our inversion the increase in depth suggested by the inversion using less rigid layers above the earthquake than below requires that more slip be placed on the fault plane to match the surface deformation. We prefer the Mojave layered elastic model because it includes more realistic structure in the upper $10 \mathrm{~km}$ than does the Standard Southern California model.

[19] Our seismic data tightly constrain the mechanism of the LSM earthquake but contain relatively little information on the location. The Mojave model predicts a slightly deeper event $(11.8 \mathrm{~km})$ than the Standard Southern California model $(10.9 \mathrm{~km})$, but most other parameters are similar. Both layered elastic models predict mechanisms that are well within the range of predictions from previous seismic studies. Both of these mechanisms fit our seismic data very well but do not fit the InSAR data well because of the poorly constrained location. Table 4 shows the misfit to InSAR and seismic data for our different sets of models and for some of the seismic locations and mechanisms.

[20] Our initial attempt at a simultaneous joint inversion calculates misfits to both our seismic and InSAR data. The correct relative weighting of the two data types is difficult to determine, as errors in InSAR data are poorly understood. We weighted the data based on the RMS value of each data type. This inversion approach results in models that average the parameters from the InSAR-only and seismic-only inversions and fit neither data set well. Using the InSAR data to relocate the best fitting mechanism inferred from only our seismic data produces a better result. We iterate between seismic-only and InSAR-only inversions multiple times. This process is much more cost-effective than the computationally expensive simultaneous inversion. Table 1 summarizes the results of this inversion and Figure 5 shows the mechanism for the Mojave elastic model and the associated misfits. This result fits both our seismic and the InSAR data well (Table 4). Synthetic waveforms calculated from the best fitting mechanism from the inversion using only InSAR data do not fit our seismic data nearly as well as does the one from the joint inversion (Figure 5). The joint InSAR/seismic inversion in the Mojave layered produces a mechanism that is $1 \mathrm{~km}$ shallower than the InSAR-only inversion in a half-space and predicts a moment of $3.2 \times 10^{17} \mathrm{~N} \mathrm{~m}\left(M_{w} 5.6\right)$. Our joint inversion constrains $\Delta L_{w m}$ to be around $5 \mathrm{~mm}$. Figure 6 shows $\Delta L_{w m}$ versus the RMS misfit to our InSAR data for models calculated during our joint inversion in the Mojave layered elastic model.

[21] Since the InSAR data provide additional constraint on the location of any given mechanism, it is useful to examine previous solutions for the LSM earthquake and their effects on the estimates of $\Delta L_{w m}$. We first compare predictions from the fault plane solutions used previously by Wernicke et al. [1998] and Savage et al. [1999] with the InSAR data (Figure 7). All three models have significant residuals when subtracted from the InSAR data (Figure 7). We relocate these three mechanisms, allowing the location and amount of slip to vary but keeping the strike, dip, rake, and fault area fixed. All three mechanisms relocate to within $500 \mathrm{~m}$ of each other (Figure 8) and predict similar residuals (Figure 7). These relocated fault planes fit the InSAR data almost as well as our best fitting solutions and predict Wahomie-Mile line length changes of 


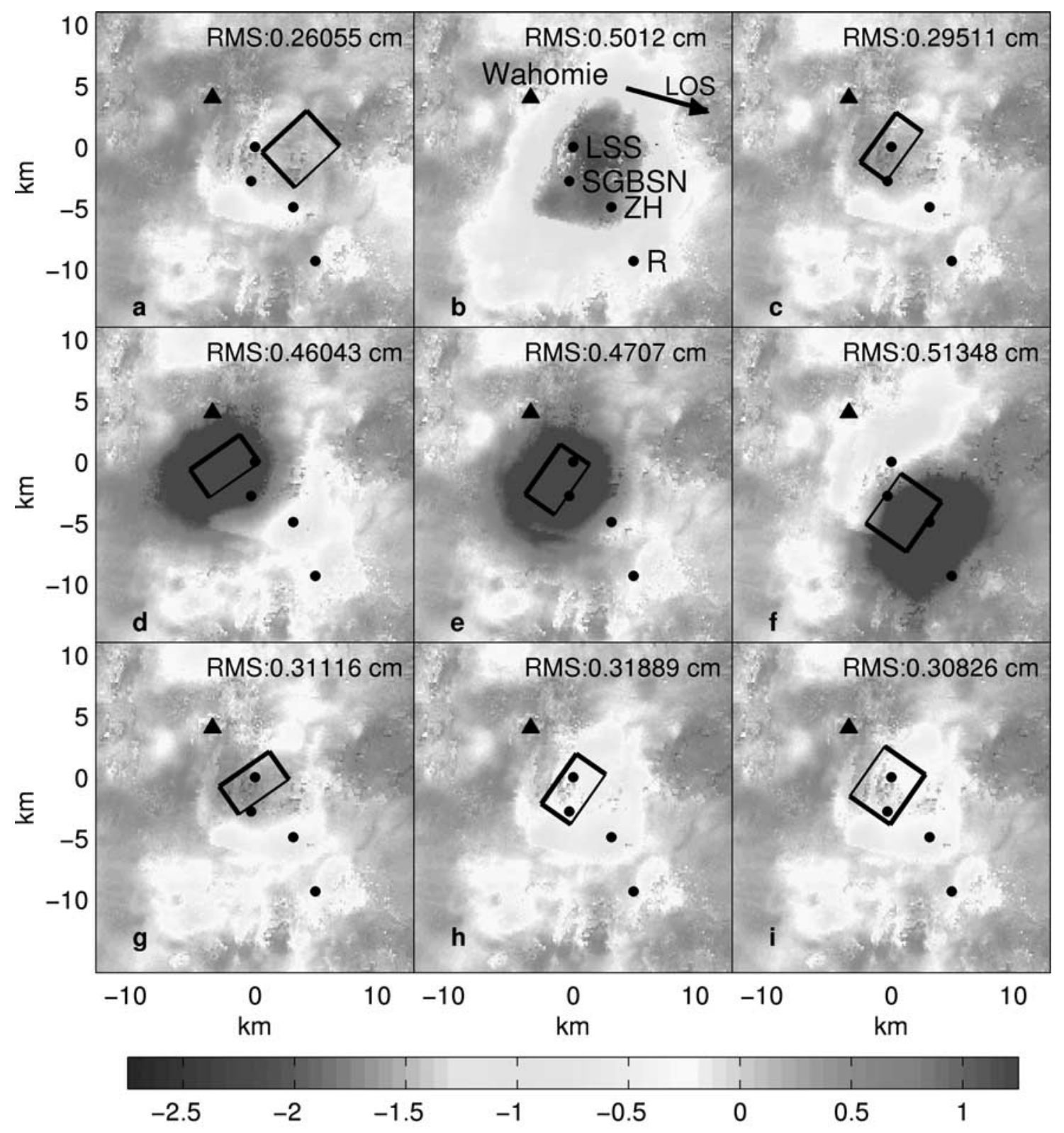

\section{LOS deformation, $\mathrm{cm}$}

Figure 7. RMS residuals between various models and the interferogram. The color scale is the same for each panel. The surface projection of the fault plane used in each case is shown by the rectangle, with the bottom of the plane as a thin line. The location of bench mark Wahomie is shown as a triangle. (a) Residual between the interferogram and the best model from our inversion in the Mojave layered space using just InSAR data, area fixed at $25 \mathrm{~km}^{2}$. (b) The original interferogram. (c) Residual between the interferogram and the best model from our joint InSAR-seismic inversion in the Mojave layered model. (d, e, f) Residuals for the models used by Savage et al. [1999] and the SE dipping and NW dipping planes of Wernicke et al. [1998], respectively. (g, h, i) Residuals for the same three models after relocation. We fix the strike, dip, rake, and area of each of the three models and allow the $(x, y, z)$ position and amount of slip to vary. Solid circles indicate LSM epicenter locations as in Figure 2. See color version of this figure at back of this issue.

4-5 $\mathrm{mm}$. These relocations show that although the InSAR and seismic data cannot unambiguously distinguish between the two potential rupture planes, they require that both fault planes centers are at approximately the same location. The two planes therefore affect the $\Delta L_{w m}$ similarly, since they are effectively point sources. We also relocate the mechanism of Smith et al. [2000], resulting in a hypocenter that is within $2 \mathrm{~km}$ of our best model. This 


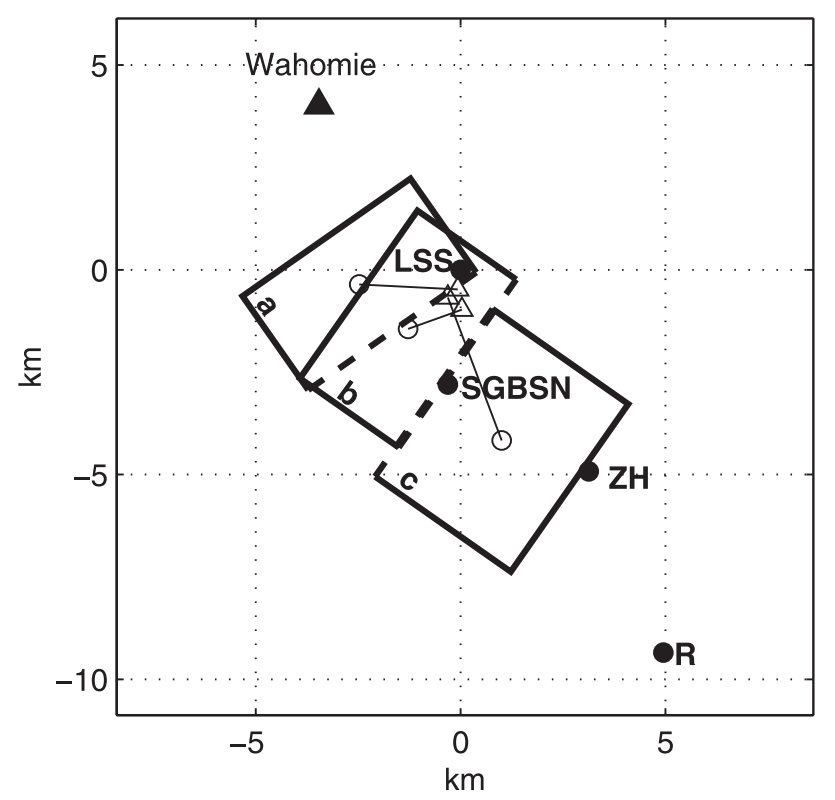

Figure 8. Rectangles indicate original positions of the SE dipping plane used by Savage et al. [1999] (rectangle a) and the SE (rectangle b) and NW (rectangle c) dipping planes of Wernicke et al. [1998]. The bottom of each plane is dashed, and the center of the original plane is shown as a circle. Our relocated centers are plotted as triangles, demonstrating that all three cluster within a few hundred meters of each other. Solid circles indicate LSM epicenter locations as in Figure 2.

model fits the InSAR and seismic data worse than either our best model or the other relocated mechanisms.

\section{Conclusions}

[22] InSAR data can effectively locate shallow earthquakes that are too small or too distant to accurately locate using traditional seismic methods. In this study, the InSAR data are sensitive to the seismic moment of the earthquake but suffer from a trade-off between mechanism and location. Our seismic data are sensitive to the mechanism but not very sensitive to the location. For the LSM earthquake, both data types are unable to separate area from magnitude of slip or to distinguish which of the two potential conjugate planes ruptured. The main observational limitations of this study are the availability of only one SAR image before the earthquake and the existence of only one component of deformation.

[23] Despite the lack of many independent interferograms, the different sets of models that we consider all have $<3 \mathrm{~mm}$ of RMS misfit with the InSAR data, with peak misfits of $\sim 1.5 \mathrm{~cm}$. All earthquake mechanisms that fit both the InSAR and seismic data have similar effects on $\Delta L_{w m}$, with a predicted elongation of 4-8 $\mathrm{mm}$ (Figure 6). This estimate of $\Delta L_{w m}$ is consistent with predictions from the SE dipping planes of both Wernicke et al. [1998] and Savage et al. [1999]. Regional strain rates predicted using these corrections agree within $2 \sigma$ error but not at the $1 \sigma$ level [Wernicke et al., 1998; Savage et al., 1999].
[24] We find that it is important to consider the effect of layered elastic models in inversions of this type. In this case, inversions in layered models produced deeper events than those in a half-space, with up to $25 \%$ differences in estimated moment release. Hopefully, future studies of small earthquakes will have more independent interferograms and therefore will permit greater averaging to reduce noise. We must also be able to measure multiple components of the deformation in order to improve the ability of InSAR data to determine earthquake mechanisms.

[25] Beyond the discussion of the LSM earthquake, this study supports the feasibility of the formation of a catalogue of earthquakes located using both InSAR and seismic data. This catalogue could support tomographic studies which can benefit from improved bounds on source locations. In many regions of the world, local seismic networks do not exist, and teleseismic and remote sensing data are the only sources of information about earthquake parameters. In these areas, teleseismic earthquake locations often have errors $>50 \mathrm{~km}$. For many of these events this uncertainty in location can be reduced by 2 orders of magnitude using joint inversions of InSAR and seismic data. Routine analysis of this sort requires the availability of a sufficiently large set of SAR data, such that there exist interferometrically useful images before and after all earthquakes of interest. Ideally, this SAR data library would include multiple sets of interferograms with ascending and descending pairs bracketing most earthquakes. A substantially more accurate earthquake catalogue will provide critical input to tectonic studies in regions with shallow seismicity and poor seismic station coverage.

[26] Acknowledgments. We are grateful to B. Wernicke and N. Niemi for helpful discussions, to R. Bennett and J. Savage for clarifying previous work, to M. Sambridge for the use of and advice about the Neighborhood Algorithm, and to D. Helmberger and H. Kanamori for their assistance in interpreting our seismic data. The GMT mapping software [Wessel and Smith, 1998] was used to prepare figures. R. Lohman is partially supported by a National Science Foundation Graduate Fellowship. B. Savage is supported by the Defense Threat Reduction Agency under contract DSWA01-98-1-0010. Contribution 8804, Division of Geological and Planetary Sciences, California Institute of Technology, Pasadena, California.

\section{References}

Ferrill, D. A., S. M. J. J. A. Stamatakos, H. L. M. B. Rahe, R. H. Martin, and A. P. Morris, Quaternary slip history of the Bare Mountain fault (Nevada) from the morphology and distribution of alluvial fan deposits, Geology, 24, 559-562, 1996.

Fridrich, C. J., Tectonic evolution of the Crater Flat basin, Yucca Mountain region, Nevada, Cenozoic Basins of the Death Valley Region, edited by L. A. Wright and B. W. Troxel, Spec. Pap. Geol. Soc. Am., 333, 169$195,1999$.

Fridrich, C. J., J. W. Whitney, M. R. Hudson, and B. M. Crowe, Space-time patterns of late Cenozic extension, verticl axis rotation, and volcanism in the Crater Flat basin, southwest Nevada, Cenozoic Basins of the Death Valley Region, edited by L. A. Wright and B. W. Troxel, Spec. Pap. Geol. Soc. Am., 333, 197-212, 1999.

Frizzell, V. A., and J. C. Shulters, Geologic map of the Nevada Test Site, southern Nevada, scale 1:100,000, U. S. Geol. Surv. Rep. I-2046, 1990.

Hadley, D., and H. Kanamori, Seismic structure of the Transverse Ranges, California, Geol. Soc. Am. Bull., 88, 1469-1478, 1977.

Harmsen, S. C. The Little Skull Mountain, Nevada, earthquake of 29 June 1992: Aftershock focal mechanisms and tectonic stress field implications, Bull. Seismol. Soc. Am., 84, 1484-1505, 1994.

Heizler, M. T., F. V. Perry, B. M. Crowe, L. Peters and R. Appelt, The age of Lathrop Wells volcanic center: $\mathrm{An}{ }^{40} \mathrm{Ar}{ }^{39} \mathrm{Ar}$ dating investigation, J. Geophys. Res., 104, 767-804, 1999.

Jones, L. E., and D. V. Helmberger, Earthquake source parameters and fault 
kinetics in the eastern California shear zone, Bull. Seismol. Soc. Am., 88 , $1337-1352,1998$

Massonnet, D., and K. L. Feigl, Radar interferometry and its application to changes in the Earth's surface, Rev. Geophys., 36, 441-500, 1997.

Meremonte, M., J. Gomberg, and E. Cranswick, Constraints on the 29 June 1992 Little Skull Mountain, Nevada, earthquake sequence provided by robust hypocenter estimates, Bull. Seismol. Soc. Am., 85, 1039-1049, 1995.

Okada, Y., Surface deformation due to shear and tensile faults in a half space, Bull. Seismol. Soc. Am., 75, 1135-1154, 1985.

Romanowicz, B., D. Dreger, M. Pasyanos, and R. Uhrhammer, Monitoring of strain release in central and northern California using broadband data Geophys. Res. Lett., 20, 1643-1646, 1993.

Rosen, P. A., S. Hensley, I. R. Joughin, F. K. Li, S. N. Madsen, E. Rodriguez, and R. M. Goldstein, Synthetic aperture radar interferometry, Proc. IEEE, 88, 333-382, 2000

Sambridge, M., Geophysical inversion with a neighborhood algorithm, I, Searching a parameter space, Geophys. J. Int., 138, 479-494, 1998a.

Sambridge, M., Geophysical inversion with a neighborhood algorithm II, Appraising the ensemble, Geophys. J. Int., 138, 727-746, 1998b.

Savage, J. C., M. Lisowski, W. K. Gross, N. E. King, and J. L. Svarc, Strain accumulation near Yucca Mountain, Nevada, 1983-1993, J. Geophys. Res., 99, 18,103-18,107, 1994

Savage, J. C., J. L. Svarc, and W. H. Prescott, Strain accumulation at Yucca Mountain, Nevada, 1983-1998, J. Geophys. Res., 104, 17,627-17,631, 1999.

Sawyer, D. A., R. J. Fleck, M. A. Lanphere, R. G. Warren, D. E. Broxton, and M. R. Hudson, Episodic caldera volcanism in the Miocene southwestern Nevada volcanic field: Revised stratigraphic framework, ${ }^{40} \mathrm{Ar}{ }^{39} \mathrm{Ar}$ geochronology, and implications for magmatism and extension, Geol. Soc. Am. Bull., 106, 1304-1318, 1994.
Smith, K. D., J. N. Brune, D. dePolo, M. K. Savage, R. Anooshehpoor, and A. F. Sheehan, The 1992 Little Skull Mountain earthquake sequence, Southern Nevada Test Site, U. S. Geol. Surv. Digital Data Ser., DDS058, K1-K16, 2000.

Wallace, R. E., Patterns and timing of late Quaternary faulting in the Great Basin Province and relation to some regional tectonic features, J. Geophys. Res., 89, 5763-5769, 1984.

Walter, W., Source parameters of the June 29, 1992 Little Skull Mountain earthquake from complete regional waveforms at a single station, Geophys. Res. Lett., 20, 403-406, 1993.

Wang, C. Y., and R. B. Herrmann, A numerical study of $P, S V$, and $S H$-wave generation in a plane layered medium, Bull. Seismol. Soc. Am., 70, 1015-1036, 1980.

Wernicke, B., J. L. Davis, R. A. Bennett, P. Elosegui, M. J. Abolins, R. J. Brady, M. A. House, N. A. Niemi, and J. K. Snow, Anomalous strain accumulation in the Yucca Mountain area, Nevada, Science, 279, 2096$2100,1998$.

Wessel, P., and W. H. F. Smith, New improved version of the Generic Mapping Tools released, Eos Trans. AGU, 79(47), 579, 1998.

Zhao, L., and D. V. Helmberger, Source estimation from broadband regional seismograms, Bull. Seismol. Soc. Am., 84, 91-104, 1994.

Zreda, M. G., F. M. Phillips, P. W. Kubik, P. Sharma, and D. Elmore, Cosmogenic ${ }^{36} \mathrm{C}$ dating of a young basaltic eruption complex, Lathrop Wells, Nevada, Geology, 82, 57-60, 1993

R. B. Lohman, B. Savage, and M. Simons, Seismological Laboratory, California Institute of Technology, 1200 E. California Blvd., Pasadena, CA 91125, USA. (fisheggs@gps.caltech.edu; savage13@gps.caltech.edu; simons@gps.caltech.edu) 


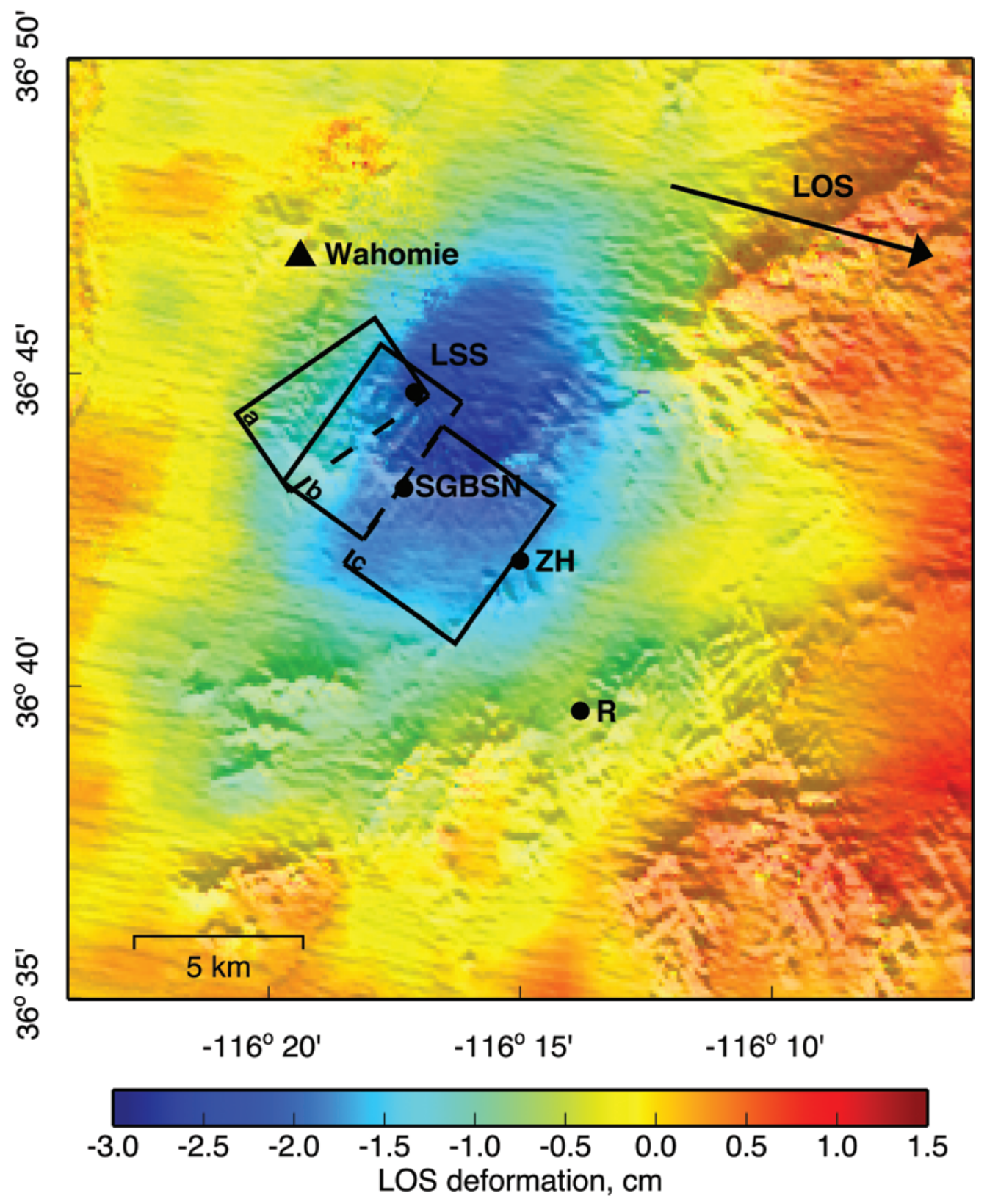

Figure 2. Averaged interferometric LOS displacement field used in the inversions. The arrow indicates the surface projection of the LOS vector from the ground to the satellite. Small-scale fluctuations in the displacement field are due to tropospheric and ionospheric variations between scene acquisition dates. Geodetic bench mark Wahomie is shown as a solid triangle. Solid circles indicate the LSM epicenter locations from the Southern Great Basin Seismic Network (SGBSN), Zhao and Helmberger [1994] (ZG), Romanowicz et al. [1993] (R) and from our joint inversion using the Mojave layered model (LSS). Rectangles show the map view projections of the fault planes used by Savage et al. [1999] (box a) and the SE dipping (box b) and NW dipping (box c) planes of Wernicke et al. [1998]. The dashed line indicates the bottom of the plane in all cases. Mercator projection. 


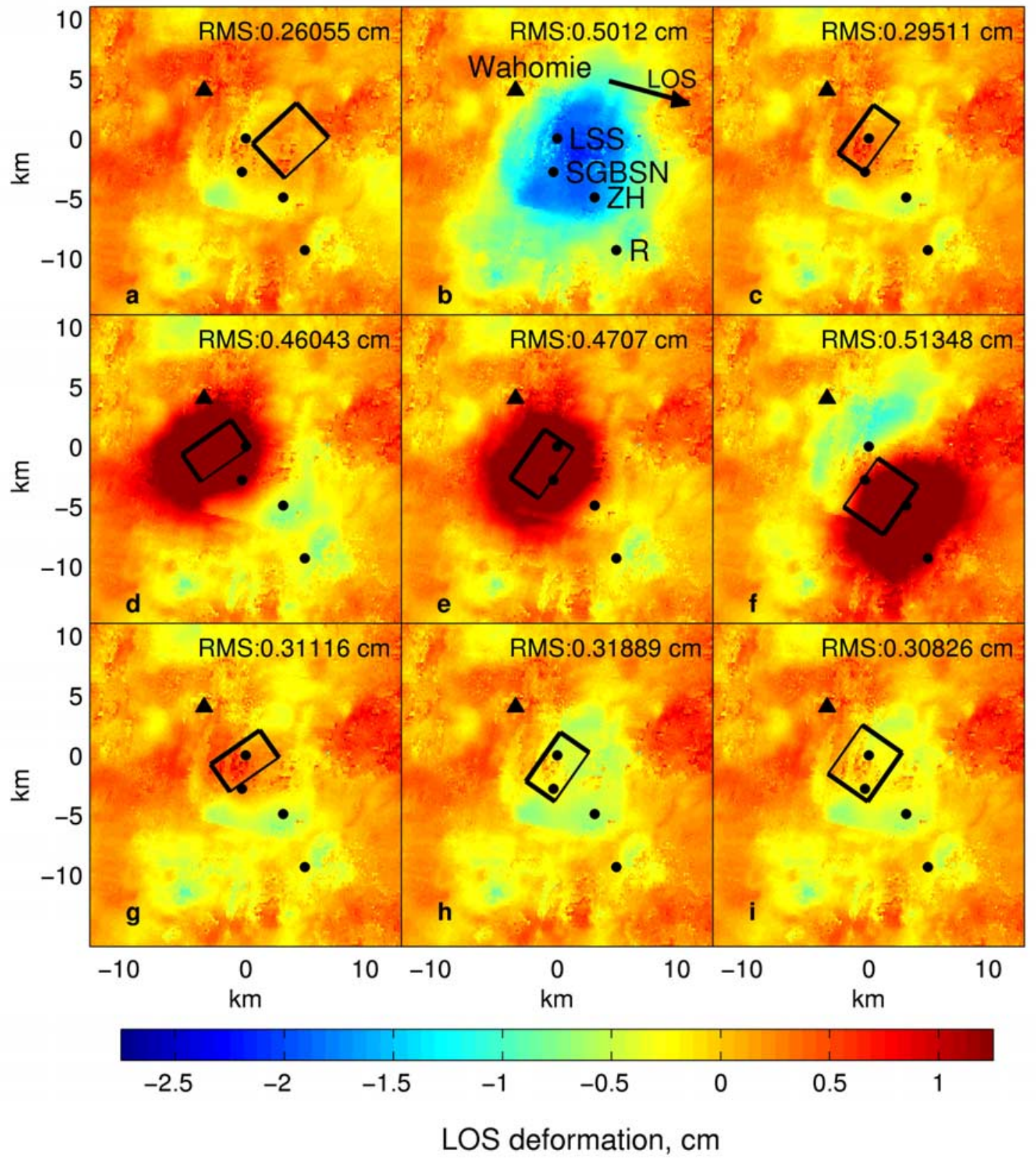

Figure 7. RMS residuals between various models and the interferogram. The color scale is the same for each panel. The surface projection of the fault plane used in each case is shown by the rectangle, with the bottom of the plane as a thin line. The location of bench mark Wahomie is shown as a triangle. (a) Residual between the interferogram and the best model from our inversion in the Mojave layered space using just InSAR data, area fixed at $25 \mathrm{~km}^{2}$. (b) The original interferogram. (c) Residual between the interferogram and the best model from our joint InSAR-seismic inversion in the Mojave layered model. (d, e, f) Residuals for the models used by Savage et al. [1999] and the SE dipping and NW dipping planes of Wernicke et al. [1998], respectively. (g, h, i) Residuals for the same three models after relocation. We fix the strike, dip, rake, and area of each of the three models and allow the $(x, y, z)$ position and amount of slip to vary. Solid circles indicate LSM epicenter locations as in Figure 2. 